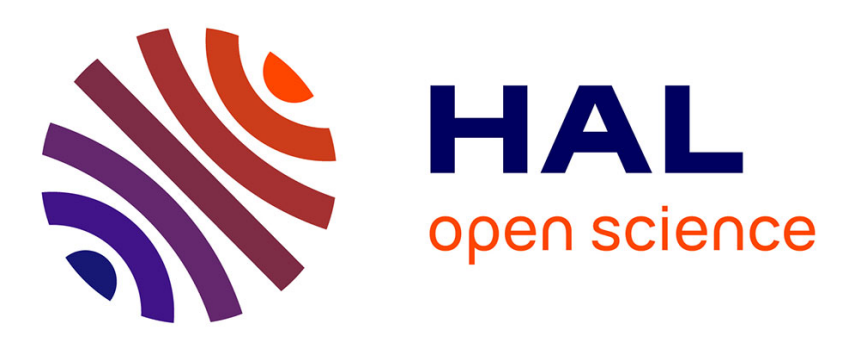

\title{
New experimental evidence and modeling study of the ethylbenzene oxidation
}

\author{
Benoit Husson, Maude Ferrari, Olivier Herbinet, Syed Sayeed Ahmed, \\ Pierre-Alexandre Glaude, Frédérique Battin-Leclerc
}

\section{- To cite this version:}

Benoit Husson, Maude Ferrari, Olivier Herbinet, Syed Sayeed Ahmed, Pierre-Alexandre Glaude, et al. New experimental evidence and modeling study of the ethylbenzene oxidation. Proceedings of the Combustion Institute, 2013, 34 (1), pp.325-333. 10.1016/j.proci.2012.06.002 hal-00772058

\section{HAL Id: hal-00772058 https://hal.science/hal-00772058}

Submitted on 9 Jan 2013

HAL is a multi-disciplinary open access archive for the deposit and dissemination of scientific research documents, whether they are published or not. The documents may come from teaching and research institutions in France or abroad, or from public or private research centers.
L'archive ouverte pluridisciplinaire HAL, est destinée au dépôt et à la diffusion de documents scientifiques de niveau recherche, publiés ou non, émanant des établissements d'enseignement et de recherche français ou étrangers, des laboratoires publics ou privés. 


\title{
New experimental evidence and modeling study of the ethylbenzene oxidation
}

\author{
Benoit Husson $^{a}$, Maude Ferrari ${ }^{a}$, Olivier Herbinet ${ }^{a}$, Syed S. Ahmed ${ }^{b}$, Pierre-Alexandre \\ Glaude $^{\mathrm{a}}$, Frédérique Battin-Leclerc ${ }^{\mathrm{a} *}$ \\ ${ }^{a}$ CNRS, Université de Lorraine, 1, rue Grandville, BP 20451, Nancy Cedex 54001, France \\ ${ }^{b}$ Saudi-Aramco Research \& Development Center, P.O. Box 1657, Ras Tanura 31311, Saudi Arabia
}

\begin{abstract}
A study of the oxidation of ethylbenzene has been performed in a jet-stirred reactor (JSR) at quasiatmospheric pressure (800 Torr), at temperatures ranging 750-1100 K, at a mean residence time of $2 \mathrm{~s}$ and at three equivalence ratios $\phi(0.25,1$, and 2$)$. Reactants and 25 reaction products were analyzed online by gas chromatography after sampling in the outlet gas. A new mechanism for the oxidation of ethylbenzene was proposed whose predictions were in satisfactory agreement with the measured species profiles obtained in JSR and with flow reactor data from the literature. A flow rate analysis has been performed at $900 \mathrm{~K}$ showing the important role of the combinations with $\mathrm{HO}_{2}$ radicals of resonance stabilized radicals obtained from ethylbenzene by $\mathrm{H}$-atom abstractions. Other important reactions of ethylbenzene are the ipso-additions of $\mathrm{H}$ - and $\mathrm{O}$-atoms and of methyl radicals to the aromatic ring.
\end{abstract}

Keywords: Ethylbenzene; Oxidation; Jet-stirred reactor; Modeling; Alkyl-benzene

\author{
Corresponding author: \\ Frédérique BATTIN-LECLERC \\ Laboratoire Réactions et Génie des Procédés \\ Ecole Nationale Supérieure des Industries Chimiques \\ BP 20451, 1 rue Grandville, 54000 Nancy, France \\ Tel: +33 (0)3 83175125 \\ Fax: +33 (0)3 83178120 \\ E-mail: frederique.battin-leclerc@univ-lorraine.fr
}




\section{Introduction}

When benzyl radicals are formed in a mixture with methyl radicals, ethylbenzene can be rapidly produced. The chemistry of the oxidation of ethylbenzene is then important for predictive modeling of both the reactions of toluene, which is currently proposed as a surrogate of aromatic compounds in gasoline-like mixtures [1], and those of larger alkylbenzene compounds which are constituents of diesel fuels [2].

In the last 30 years, studies on the oxidation of ethylbenzene were already performed in a static reactor (as an additive in a $\mathrm{H}_{2} / \mathrm{O}_{2}$ mixture at $772 \mathrm{~K}$ ) [3], in a flow reactor (temperatures from 1056 to $1200 \mathrm{~K}$ ) [4] and [5], in a rapid compression machine (temperatures from 600 to $900 \mathrm{~K}$ ) [6] and in a shock tube (at temperatures from 941 to $1408 \mathrm{~K}$ ) [7]. However, apart from the work of Ellis et al. [3] about the addition of ethylbenzene to a $\mathrm{H}_{2} / \mathrm{O}_{2}$ mixture in static reactor, no detailed information about the formation of intermediate species during the oxidation of ethylbenzene below $1000 \mathrm{~K}$ is available in the literature. Therefore, the purpose of this study is then to present experimental results in a jet-stirred reactor for the oxidation of ethylbenzene at temperatures from 750 to $1100 \mathrm{~K}$ and to present a new detailed kinetic model for the oxidation of this $\mathrm{C}_{8}$ aromatic compound based on new experimental data.

\section{Experimental method}

The oxidation of ethylbenzene has been performed in a jet-stirred reactor, a type of reactor which has often been used for gas phase kinetic studies [8], [9] and [10]. Experiments were performed at a constant pressure of 800 Torr $(1.06 \mathrm{bar})$, at a residence time of $2 \mathrm{~s}$, at temperatures ranging $750-1100 \mathrm{~K}$ and at three equivalence ratios $(0.25,1$, and 2$)$. The fuel was diluted in helium (ethylbenzene mole fraction of 0.005). Ethylbenzene was provided by Sigma-Aldrich (purity 99\%), and helium and oxygen by Messer (purity of $99.999 \%$ for $\mathrm{He}$ and $99.995 \%$ for $\mathrm{O}_{2}$ ).

The reactor consists of a quartz sphere (volume $=95 \mathrm{~cm}^{3}$ ) into which diluted reactant enters through an injection cross located at its center. It is operated at constant temperature and pressure and it is preceded by an annular preheating zone in which the temperature of the gases is progressively increased up to the reactor temperature before entering inside. Gas mixture residence time inside the annular preheater is very short compared to its residence time inside the reactor (a few percent). Both the spherical reactor and the annular preheating zone are heated by resistance heaters wrapped around their walls. Despite the exothermicity of the reaction, the temperature gradient in the vessel was lower than $5 \mathrm{~K}$.

The fuel flow rate was controlled by a liquid mass flow controller and was mixed with the carrier gas and then evaporated by passing through a single pass heat exchanger, the temperature of which was set above the boiling point of the hydrocarbon. Carrier gas and oxygen flow rates were controlled by gas mass flow controllers. The accuracy of the liquid and gas flow rates was around $0.5 \%$.

The outlet products were analyzed online by gas chromatography. The online analysis of products which are liquid at standard conditions was performed using a heated transfer line between the reactor outlet and the chromatograph sampling gates which were also heated. During the study, the temperature of the transfer line was set at $473 \mathrm{~K}$. This temperature was high enough to keep all the reaction products in the gas phase. 
Three gas chromatographs were used for the quantification of the different species. The first gas chromatograph, equipped with a Carbosphere packed column, a thermal conductivity detector (TCD), and a flame ionization detector (FID), was used for the quantification of $\mathrm{O}_{2}, \mathrm{CO}, \mathrm{CO}_{2}$, methane, ethylene, acetylene and ethane. While detected in GC-MS, hydrogen, water and formaldehyde were not quantified. The second GC was fitted with a PlotQ capillary column and a FID, and was used for the quantification of $\mathrm{C}_{1}-\mathrm{C}_{4}$ hydrocarbons and of small oxygenated compounds. The third $\mathrm{GC}$ was fitted with a HP-5 capillary column and a FID, and was used for the quantification of hydrocarbons and oxygenated species with more than five heavy atoms (i.e., carbon and oxygen atoms). The identification and the calibration of light species (e.g., carbon oxides, $C_{1}-C_{4}$ hydrocarbons) were performed by injecting gaseous samples provided by Messer and Air Liquide. The identification of species which were not available was performed using a fourth gas chromatograph coupled with a mass spectrometer (GC-MS) operating under the same conditions as the gas chromatograph used for the quantification, enabling the direct comparison of both chromatograms. The identification of these species was not performed "online". The reaction products were condensed in a trap located at the outlet of the reactor and maintained at the temperature of liquid nitrogen. The content of the trap was then analyzed by GC-MS. The mass spectra of all detected reaction products were included in the spectra database "NIST 08".

The calibration was performed by injecting known amounts of the pure substances when available, otherwise the method of the effective carbon number was used (species having the same number of carbon atoms and the same functional groups were assumed to have the same response in the FID). The detection threshold was about $1 \mathrm{ppm}$ for the heaviest species (FID) and about $100 \mathrm{ppm}$ for carbon oxides and oxygen (TCD). Based on the repeatability of the experiments, uncertainty estimates on obtained mole fractions were about $\pm 5 \%$ (measure reading).

\section{Experimental results}

Reactants and 25 reaction products were analyzed online by gas chromatography. These species are:

- carbon oxides,

- saturated hydrocarbons, olefins and poly-unsaturated hydrocarbons: methane, ethane, ethylene, propene, 1-butene (less than $2.5 \mathrm{ppm}$ ), acetylene, propyne, allene, and 1,3-butadiene,

- aromatic hydrocarbons: benzene, toluene, styrene, cumene (isopropylbenzene), $\alpha$-methylstyrene (2-phenyl-1-propene), and 2-propenylbenzene (less than 5 ppm),

- aldehydes, ketones and alcohols: acetaldehyde, acrolein, benzaldehyde, benzofuran, phenol, cresols (methylphenols), phenylacetaldehyde, and acetophenone (methylphenylketone). These last two compounds display mass spectra clearly different from each other and from that of phenyloxirane which could have been expected.

Four additional species were detected but not quantified (concentration less than $0.1 \mathrm{ppm}$ ): anisole (methoxybenzene), ethylphenol, hydroxybenzaldehyde and naphthalene. Tables presenting the obtained experimental data are available as Supplementary data.

Figures 1 to 3 display the evolution with temperature of the reactant mole fractions (ethylbenzene and oxygen) (Figure 1) and of the reaction products with mole fraction above 5 ppm (Figures1 to 3 ). In all the figures showing experiments and simulations, points are experiments and lines model predictions. As expected since no low-temperature oxidation pathways are possible, the mole fraction profile of ethylbenzene does not exhibit any Negative Temperature Coefficient (NTC) behavior. Although experiments described in this paper are over a temperature range from 750 to 
$1100 \mathrm{~K}$, additional tests were performed at temperatures lower than $750 \mathrm{~K}$ : no conversion of the reactant and no product were observed. The reactivity starts at $800-825 \mathrm{~K}$ (depending on the equivalence ratio) with a smooth fuel consumption until 975-1000 K. The equivalence ratio had a slight effect on the ethylbenzene conversion. The shapes of the curves were similar at equivalence ratios of 1 and 0.25 . For the rich mixture (equivalence ratio of 2), a slightly lower reactivity was observed.

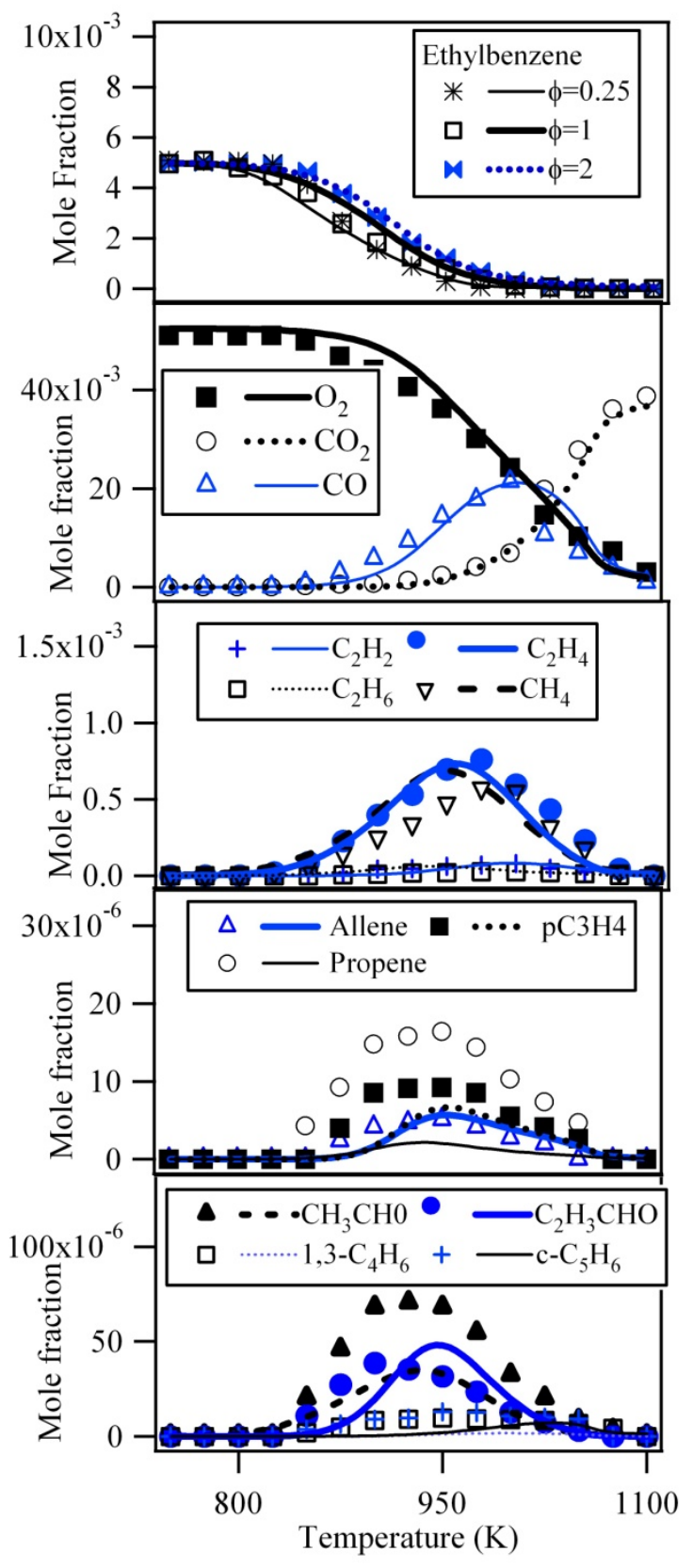

Figure 1. Jet-stirred reactor results: reactant (for three equivalence ratios) and non-aromatic product (at stoichiometric conditions) mole fraction evolution with temperature. 


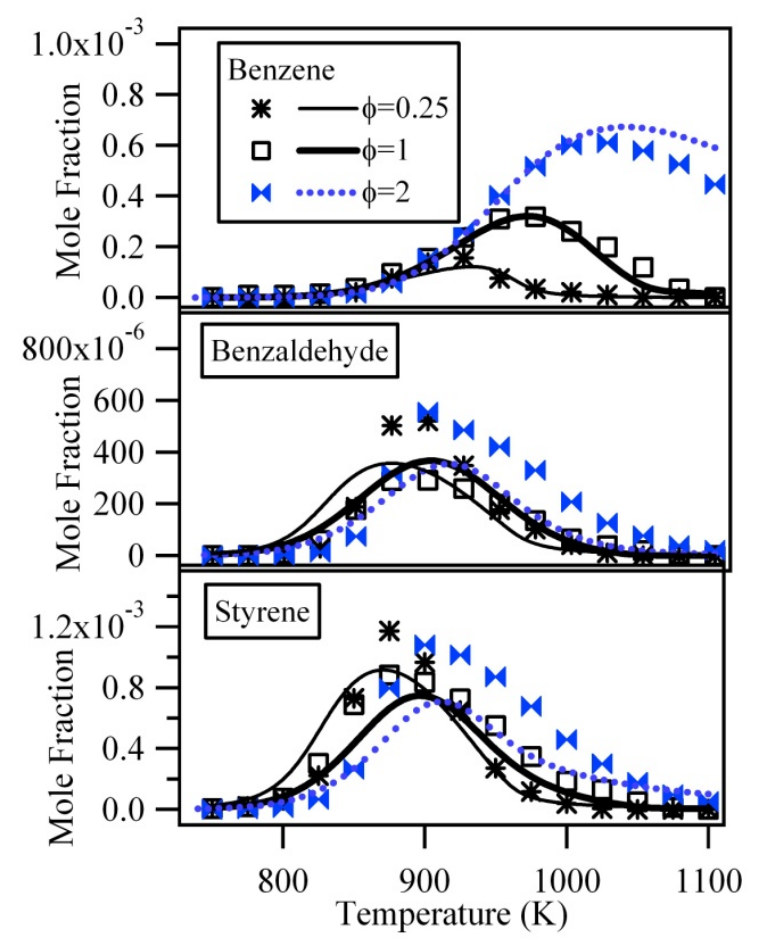

Figure 2. Jet-stirred reactor results: main monocyclic aromatic intermediate species mole fraction evolution with temperature for 3 equivalence ratios.

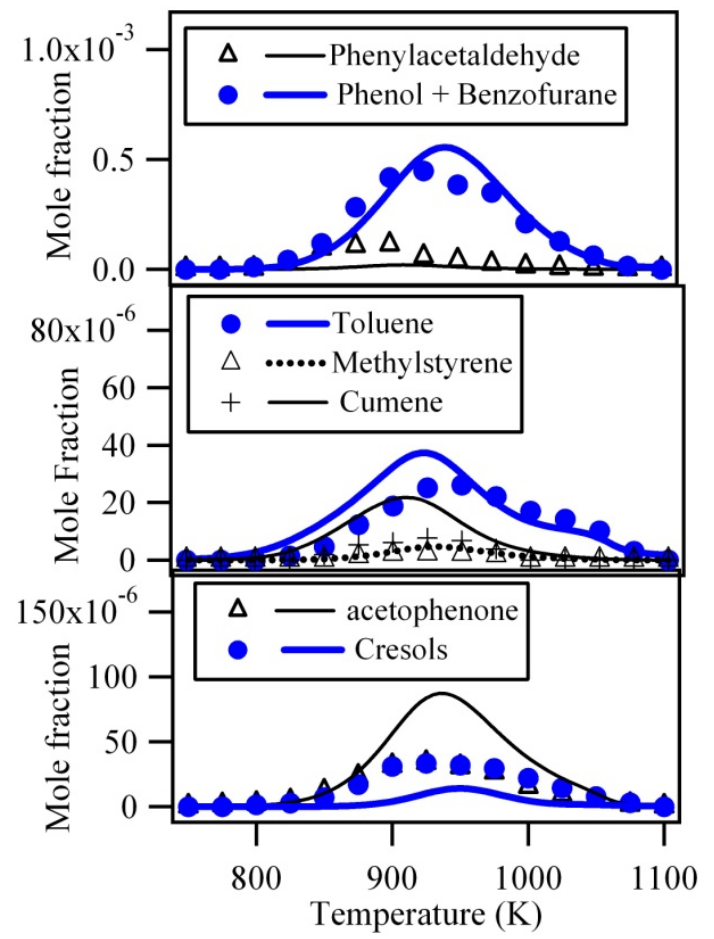

Figure 3. Jet-stirred reactor results: minor aromatic intermediate species mole fraction evolution with temperature at stoichiometric conditions. 
As shown in Figure 1, the major produced hydrocarbons were methane and ethylene with very small amounts of $\mathrm{C}_{2+}$ non-aromatic compounds (maximum mole fractions below $20 \mathrm{ppm}$ under stoichiometric conditions). The formation of these compounds was favored under rich conditions. Acetaldehyde is the major non-aromatic aldehyde (maximum mole fractions of $70 \mathrm{ppm}$ at all equivalence ratios).

As shown in Figure 2, benzene, benzaldehyde, and styrene were the major monocyclic aromatic compounds, with maximum mole fractions under stoichiometric conditions of 310, 290, and $880 \mathrm{ppm}$, respectively. While the formation of benzene significantly increases as equivalence ratio increases, the formation of benzaldehyde, and styrene is slightly favored under rich conditions but less dependent on equivalence ratio.

As shown in Figure 3 in stoichiometric conditions, other monocyclic aromatic hydrocarbons (toluene, methylstyrene and cumene) are formed in lower amounts (maximum mole fractions below $50 \mathrm{ppm}$ ). It has not been possible to separate the peaks of phenol and benzofuran in the chromatograms. Therefore, Figure 3 presents the sum of these two compounds formed in significant amounts (maximum mole fractions in stoichiometric mixtures of $400 \mathrm{ppm}$ ). Phenylacetaldehyde is also produced in significant amounts (maximum mole fractions in stoichiometric mixtures of $110 \mathrm{ppm}$ ), with formation notably favored in a lean mixture. Other oxygenated aromatic compounds (acetophenone, cresols) are formed in lower amounts (maximum mole fractions in stoichiometric mixtures below $60 \mathrm{ppm}$ ).

\section{Modeling}

A detailed kinetic model of the oxidation of ethyl-benzene was developed based on that proposed by Gueniche et. al [11]. This model includes a $C_{0}-C_{2}$ reaction base, a mechanism to model the oxidation of $\mathrm{C}_{3}-\mathrm{C}_{5}$ unsaturated hydrocarbons, especially allene, propyne, 1,3-butadiene and cyclopentene, as well as mechanisms for the oxidation of small aromatic compounds, benzene [12] and toluene [8]. The full mechanism involves 205 species included in 1411 reactions. We improved this mechanism in order to be able to correctly model the present experimental data for the oxidation of ethylbenzene. The mechanism formatted to be used with CHEMKIN software [13] is available as Supplementary data.

Thermochemical data were mainly estimated by the software THERGAS [14], which is based on the group additivity methods proposed by Benson [15], apart from the heat of formation of some species (see comments in the provided mechanism), which were taken from Goos et al. [16] (case of biaromatic species) or re-evaluated using quantum calculations performed by Gaussian09 [17] at the CBS-QB3 level of theory [18].

The mechanism of Gueniche et. al. [11] has been first checked for the consistency between kinetic and thermochemical data by calculating the reverse rate constant of every reaction and needed corrections have been made. Then a few updates of the reactions of the $C_{0}-C_{6}$ species have been made (see Supplementary data). The rate parameters of 4 reactions of the $C_{0}-C_{2}$ reaction base and those of 15 reactions of $C_{3}-C_{5}$ unsaturated hydrocarbons have been updated to use more recent values, e.g., the recent value from Troe [19] for the decomposition of $\mathrm{H}_{2} \mathrm{O}_{2}$. Estimated rate constants for $\mathrm{H}$-abstractions have been changed by literature values in the case of those from benzene by allyl radical [20], and those from phenol by $C_{3}-C_{5}$ radicals [21]. The combination of hydroxyphenyl and methyl radicals has been added. The new rate constants proposed by Tian et al. [22] to model toluene flames, as well as the recent changes proposed by Herbinet et al. [23] to model the low- 
temperature (from $500 \mathrm{~K}$ ) oxidation of toluene with $n$-decane as a co-reactant (see Supplementary data) have been considered.

A short sub-mechanism of the oxidation of ethylbenzene was already considered in the secondary mechanism of the oxidation of toluene proposed by Bounaceur et al. [8]. Based on this first attempt, a new primary mechanism for the oxidation of ethylbenzene has been written and is presented in Table 1, as well as the references related to the kinetic data. Note that very few data are available in the literature concerning the rate constants involved in this mechanism.

Table 1. Primary mechanism of the oxidation of ethylbenzene.

\begin{tabular}{|c|c|c|c|c|c|}
\hline Reactions & $A$ & $n$ & $E_{\mathrm{a}}$ & References & $n^{\circ}$ \\
\hline \multicolumn{6}{|l|}{ Umimolecular initiation } \\
\hline et $\mathrm{C}_{6} \mathrm{H}_{5}=\mathrm{C}_{8} \mathrm{H}_{9}+\mathrm{H}$ & $4.3 \times 10^{14}$ & 0.0 & 83.6 & Estimated $^{\mathrm{a}}$ & (1) \\
\hline \multicolumn{6}{|l|}{ Bimolecular initiations } \\
\hline et $\mathrm{C}_{6} \mathrm{H}_{5}+\mathrm{O}_{2}=\mathrm{C}_{8} \mathrm{H}_{9}+\mathrm{HO}_{2}$ & $1.4 \times 10^{12}$ & 0.0 & 34.0 & Estimated $^{\mathrm{b}}$ & $(2)$ \\
\hline et $\mathrm{C}_{6} \mathrm{H}_{5}+\mathrm{O}_{2}=\mathrm{C}_{8} \mathrm{H}_{9}-1+\mathrm{HO}_{2}$ & $1.2 \times 10^{13}$ & 0.0 & 49.0 & Estimated $^{c}$ & (3) \\
\hline \multicolumn{6}{|l|}{ Ipso-additions } \\
\hline et $_{6} \mathrm{H}_{5}+\mathrm{H}=\mathrm{C}_{6} \mathrm{H}_{6}+\mathrm{C}_{2} \mathrm{H}_{5}$ & $5.8 \times 10^{13}$ & 0.0 & 8.1 & Estimated $^{d}$ & (4) \\
\hline et $\mathrm{C}_{6} \mathrm{H}_{5}+\mathrm{O}=\mathrm{C}_{6} \mathrm{H}_{5} \mathrm{O}+\mathrm{C}_{2} \mathrm{H}_{5}$ & $1.7 \times 10^{13}$ & 0.0 & 3.6 & Estimated $^{d}$ & (5) \\
\hline etC $_{6} \mathrm{H}_{5}+\mathrm{OH}=\mathrm{C}_{6} \mathrm{H}_{5} \mathrm{OH}+\mathrm{C}_{2} \mathrm{H}_{5}$ & $1.3 \times 10^{13}$ & 0.0 & 10.6 & Estimated $^{d}$ & (6) \\
\hline et $\mathrm{C}_{6} \mathrm{H}_{5}+\mathrm{CH}_{3}=$ toluene $+\mathrm{C}_{2} \mathrm{H}_{5}$ & $1.2 \times 10^{12}$ & 0.0 & 12.4 & Estimated $^{\mathrm{e}}$ & (7) \\
\hline \multicolumn{6}{|l|}{ Metatheses } \\
\hline et $\mathrm{C}_{6} \mathrm{H}_{5}+\mathrm{H}=\mathrm{C}_{8} \mathrm{H}_{9}+\mathrm{H}_{2}$ & $8.0 \times 10^{13}$ & 0.0 & 6.4 & Estimated $^{f}$ & (8) \\
\hline et $\mathrm{C}_{6} \mathrm{H}_{5}+\mathrm{O}=\mathrm{C}_{8} \mathrm{H}_{9}+\mathrm{OH}$ & $4.2 \times 10^{11}$ & 0.0 & -2.0 & Estimated $^{f}$ & (9) \\
\hline et $_{6} \mathrm{H}_{5}+\mathrm{OH}=\mathrm{C}_{8} \mathrm{H}_{9}+\mathrm{H}_{2} \mathrm{O}$ & $3.5 \times 10^{9}$ & 1.0 & -1.13 & Estimated $^{f}$ & (10) \\
\hline et $\mathrm{C}_{6} \mathrm{H}_{5}+\mathrm{HO}_{2}=\mathrm{C}_{8} \mathrm{H}_{9}+\mathrm{H}_{2} \mathrm{O}_{2}$ & $2.7 \times 10^{11}$ & 0.0 & 12.0 & Estimated $^{f}$ & (11) \\
\hline $\mathrm{etC}_{6} \mathrm{H}_{5}+\mathrm{CH}_{3}=\mathrm{C}_{8} \mathrm{H}_{9}+\mathrm{CH}_{4}$ & $1.1 \times 10^{12}$ & 0.0 & 9.1 & Estimated $^{f}$ & $(12)$ \\
\hline etC $_{6} \mathrm{H}_{5}+\mathrm{C}_{3} \mathrm{H}_{5}=\mathrm{C}_{8} \mathrm{H}_{9}+\mathrm{C}_{3} \mathrm{H}_{6}$ & $1.1 \times 10^{12}$ & 0.0 & 13.1 & Estimated $^{f}$ & (13) \\
\hline et $\mathrm{C}_{6} \mathrm{H}_{5}+\mathrm{iC}_{4} \mathrm{H}_{5}=\mathrm{C}_{8} \mathrm{H}_{9}+1,3-\mathrm{C}_{4} \mathrm{H}_{6}$ & $1.1 \times 10^{12}$ & 0.0 & 13.1 & Estimated $^{f}$ & (14) \\
\hline et $\mathrm{C}_{6} \mathrm{H}_{5}+\mathrm{nC}_{4} \mathrm{H}_{5}=\mathrm{C}_{8} \mathrm{H}_{9}+1,3-\mathrm{C}_{4} \mathrm{H}_{6}$ & $1.1 \times 10^{12}$ & 0.0 & 13.1 & Estimated $^{\mathrm{f}}$ & (15) \\
\hline et $\mathrm{C}_{6} \mathrm{H}+\mathrm{C}_{5} \mathrm{H}_{5}=\mathrm{C}_{8} \mathrm{H}_{9}+\mathrm{C}_{5} \mathrm{H}_{6}$ & $1.1 \times 10^{12}$ & 0.0 & 13.1 & Estimated $^{f}$ & (16) \\
\hline et $\mathrm{C}_{6} \mathrm{H}_{5}+\mathrm{C}_{6} \mathrm{H}_{5}=\mathrm{C}_{6} \mathrm{H}_{6}+\mathrm{C}_{8} \mathrm{H}_{9}$ & $5.3 \times 10^{13}$ & 0.0 & 9.0 & Estimated $^{\mathrm{g}}$ & (17) \\
\hline et $\mathrm{C}_{6} \mathrm{H}_{5}+\mathrm{C}_{6} \mathrm{H}_{5} \mathrm{O}=\mathrm{C}_{8} \mathrm{H}_{9}+\mathrm{C}_{6} \mathrm{H}_{5} \mathrm{OH}$ & $1.1 \times 10^{12}$ & 0.0 & 13.1 & Estimated $^{f}$ & (18) \\
\hline et $\mathrm{C}_{6} \mathrm{H}_{5}+$ benzyl $=\mathrm{C}_{8} \mathrm{H}_{9}+$ toluene & $1.1 \times 10^{12}$ & 0.0 & 13.1 & Estimated $^{f}$ & (19) \\
\hline et $\mathrm{C}_{6} \mathrm{H}_{5}+\mathrm{OC}_{6} \mathrm{H}_{4} \mathrm{CH}_{3}=\mathrm{C}_{8} \mathrm{H}_{9}+\mathrm{HOC}_{6} \mathrm{H}_{4} \mathrm{CH}_{3}$ & $1.1 \times 10^{11}$ & 0.0 & 13.1 & Estimated $^{f}$ & (20) \\
\hline et $\mathrm{C}_{6} \mathrm{H}_{5}+\mathrm{HOC}_{6} \mathrm{H}_{4} \mathrm{CH}_{2}=\mathrm{C}_{8} \mathrm{H}_{9}+\mathrm{HOC}_{6} \mathrm{H}_{4} \mathrm{CH}_{3}$ & $1.1 \times 10^{11}$ & 0.0 & 13.1 & Estimated $^{f}$ & $(21)$ \\
\hline et $\mathrm{C}_{6} \mathrm{H}_{5}+\mathrm{H}=\mathrm{C}_{8} \mathrm{H}_{9}-1+\mathrm{H}_{2}$ & $7.2 \times 10^{8}$ & 1.5 & 6.79 & Estimated $^{\text {h }}$ & $(22)$ \\
\hline et $\mathrm{C}_{6} \mathrm{H}_{5}+\mathrm{O}=\mathrm{C}_{8} \mathrm{H}_{9}-1+\mathrm{OH}$ & $5.1 \times 10^{8}$ & 1.5 & 5.05 & Estimated $^{\text {h }}$ & (23) \\
\hline et $_{6} \mathrm{H}_{5}+\mathrm{OH}=\mathrm{C}_{8} \mathrm{H}_{9}-1+\mathrm{H}_{2} \mathrm{O}$ & $3.6 \times 10^{6}$ & 2.0 & 0.48 & Estimated $^{\text {h }}$ & (24) \\
\hline et $\mathrm{C}_{6} \mathrm{H}_{5}+\mathrm{HO}_{2}=\mathrm{C}_{8} \mathrm{H}_{9}-1+\mathrm{H}_{2} \mathrm{O}_{2}$ & $4.2 \times 10^{4}$ & 2.7 & 8.5 & Estimated $^{\mathrm{h}}$ & $(25)$ \\
\hline et $\mathrm{C}_{6} \mathrm{H}_{5}+\mathrm{CH}_{3}=\mathrm{C}_{8} \mathrm{H}_{9}-1+\mathrm{CH}_{4}$ & $2.4 \times 10^{6}$ & 1.9 & 10.3 & Estimated $^{\text {h }}$ & (26) \\
\hline et $\mathrm{C}_{6} \mathrm{H}_{5}+\mathrm{C}_{6} \mathrm{H}_{5}=\mathrm{C}_{6} \mathrm{H}_{6}+\mathrm{C}_{8} \mathrm{H}_{9}-1$ & $5.8 \times 10^{10}$ & 0.0 & 3.83 & Estimated & $(27)$ \\
\hline \multicolumn{6}{|l|}{ Reactions of derived radicals } \\
\hline $\mathrm{C}_{8} \mathrm{H}_{9}=\mathrm{H}+$ styrene & $3.1 \times 10^{13}$ & 0.0 & 50.7 & {$[24]$} & $(28)$ \\
\hline $\mathrm{C}_{8} \mathrm{H}_{9}-1=\mathrm{H}+$ styrene & $4.0 \times 10^{13}$ & 0.0 & 33.6 & Estimated $^{j}$ & (29) \\
\hline $\mathrm{C}_{8} \mathrm{H}_{9}-1=\mathrm{C}_{2} \mathrm{H}_{4}+\mathrm{C}_{6} \mathrm{H}_{5}$ & $2.0 \times 10^{13}$ & 0.0 & 35.5 & Estimated $^{c}$ & (30) \\
\hline $\mathrm{C}_{8} \mathrm{H}_{9}+\mathrm{O}_{2}=\mathrm{HO}_{2}+$ styrene & $6.9 \times 10^{11}$ & 0.0 & 15.2 & Estimated $^{k}$ & (31) \\
\hline $\mathrm{C}_{8} \mathrm{H}_{9}-1+\mathrm{O}_{2}=\mathrm{HO}_{2}+$ styrene & $2.6 \times 10^{11}$ & 0.0 & 2.5 & Estimated $^{\mathrm{k}}$ & (32) \\
\hline $\mathrm{C}_{8} \mathrm{H}_{9}-1+\mathrm{HO}_{2}=\mathrm{OH}+\mathrm{HCHO}+$ benzyl & $5.0 \times 10^{12}$ & 0.0 & 0.0 & Estimated $^{\mathrm{a}}$ & (33) \\
\hline
\end{tabular}


Table 1 (continued)

\begin{tabular}{|c|c|c|c|c|c|}
\hline $\mathrm{C}_{8} \mathrm{H}_{9}+\mathrm{HO}_{2}=\mathrm{C}_{8} \mathrm{H}_{9} \mathrm{OOH}$ & $3.6 \times 10^{12}$ & 0.0 & 0.0 & Estimated $^{\mathrm{a}}$ & (34) \\
\hline $\mathrm{C}_{8} \mathrm{H}_{9} \mathrm{OOH}=\mathrm{H}_{2} \mathrm{O}+\mathrm{C}_{6} \mathrm{H}_{5} \mathrm{COCH}_{3}$ & $1.3 \times 10^{12}$ & 2.2 & 44.9 & Estimated & (35) \\
\hline $\mathrm{C}_{8} \mathrm{H}_{9} \mathrm{OOH}=\mathrm{OH}+\mathrm{C}_{8} \mathrm{H}_{9} \mathrm{O}$ & $5.0 \times 10^{15}$ & 0.0 & 42.5 & Estimated $^{\mathrm{m}}$ & (36) \\
\hline $\mathrm{C}_{8} \mathrm{H}_{9} \mathrm{O}=\mathrm{CH}_{3}+\mathrm{C}_{6} \mathrm{H}_{5} \mathrm{CHO}$ & $2.7 \times 10^{13}$ & 0.0 & 12.1 & Estimated $^{\mathrm{n}}$ & (37) \\
\hline $\mathrm{C}_{8} \mathrm{H}_{9} \mathrm{O}=\mathrm{H}+\mathrm{C}_{6} \mathrm{H}_{5} \mathrm{COCH}_{3}$ & $9.8 \times 10^{12}$ & 0.0 & 17.2 & Estimated $^{n}$ & (38) \\
\hline $\mathrm{C}_{8} \mathrm{H}_{9} \mathrm{O}=\mathrm{C}_{6} \mathrm{H}_{5}+\mathrm{CH}_{3} \mathrm{CHO}$ & $1.7 \times 10^{14}$ & 0.0 & 20.5 & Estimated $^{\mathrm{n}}$ & (39) \\
\hline $\mathrm{C}_{8} \mathrm{H}_{9}+\mathrm{CH}_{3}=$ cumene & $1.0 \times 10^{12}$ & 0.0 & 0.0 & Estimated $^{\mathrm{a}}$ & (40) \\
\hline
\end{tabular}

Notes: The rate constants are given at $1 \mathrm{~atm}\left(k=A T^{n} \exp \left(-E_{\mathrm{a}} / R T\right)\right)$ in $\mathrm{cm}^{3}, \mathrm{~mol}, \mathrm{~s}, \mathrm{kcal}$ units.

a Rate constants of unimolecular initiations or combinations calculated using software KINGAS [25].

b Rate constant calculated using the correlations proposed by Ingham et al [26]: $A$ is taken equal to $n \times 7 \times 10^{11} \mathrm{~cm}^{3} \mathrm{~mol}^{-1} \mathrm{~s}^{-1}$, where $n$ is the number of abstractable benzylic hydrogen atoms, and the activation energy to the reaction enthalpy [14].

c Rate constant calculated using the same correlations as those used in Exgas for alkyl radicals [27].

$d$ Rate constant taken equal to that of the similar reaction in the case of toluene [8].

e Rate constant taken equal to that calculated for similar reaction in the case of benzene [28] with an activation energy $3.5 \mathrm{kcal} / \mathrm{mol}$ lower to take into account that the formed radical is an ethyl radical instead of a $\mathrm{H}$-atom.

$f$ Rate constant taken equal to that of the similar reaction in the case of toluene [8] with $A$ multiplied by $2 / 3$ to take into account the number abstractable $\mathrm{H}$-atoms and with an activation energy $2 \mathrm{kcal} / \mathrm{mol}$ lower due to the abstraction of secondary $\mathrm{H}$-atoms instead of primary ones.

g Rate constant taken equal to that of the similar reaction in the case of toluene [20] with $A$ multiplied by $2 / 3$ and with an activation energy $3 \mathrm{kcal} / \mathrm{mol}$ lower due to the abstraction of secondary $\mathrm{H}$-atoms instead of primary ones.

h Estimated using the correlation proposed by Dean et al. [29].

i Rate constant taken equal to that of the similar reaction in the case of neopentane [30] with $A$ divided by 4.

j Activation energy estimated using the Evans-Polanyi correlation proposed Sirjean et al. [31] for $\beta$-scissions of alkyl radicals. $\mathrm{k}$ Rate constant taken equal to that the oxidation of allylic radicals (for $\bullet \mathrm{C}_{6} \mathrm{H}_{5} \mathrm{CHCH}_{3}$ radicals) as proposed by Touchard et al. [32], or of alkylic radicals (for $\bullet \mathrm{C}_{6} \mathrm{H}_{5} \mathrm{CH}_{2} \mathrm{CH}_{2}$ radicals) as proposed by Warth et al. [25].

I See text.

$m$ Rate constant taken equal to those proposed by Sahetchian et al. [33] in the case of alkylhydroperoxides.

$\mathrm{n}$ Rate constant taken equal to that of the similar reaction in the case of but-3-en-1-oxy [34].

Only the unimolecular decomposition involving the breaking of the $\mathrm{C}-\mathrm{H}$ bond with lowest energy has been considered: reaction (1, numbers referring to Table 1 ) leading to the cyclic resonance stabilized $\mathrm{C}_{8} \mathrm{H}_{9}\left(\mathrm{C}_{6} \mathrm{H}_{5} \mathrm{CH} \cdot \mathrm{CH}_{3}\right)$ radicals. The decomposition involving the breaking of a $\mathrm{C}-\mathrm{C}$ bond and leading to benzyl and methyl radicals is already considered in the toluene mechanism [8]. Two types of bimolecular initiations with oxygen molecules and $\mathrm{H}$-atom abstractions with small molecules have been written: reactions ( 2 and 8-21) yielding resonance stabilized $\mathrm{C}_{8} \mathrm{H}_{9}$ radicals and reactions $(3$ and 22-27) giving $\mathrm{C}_{8} \mathrm{H}_{9}-1$ radicals $\left(\mathrm{C}_{6} \mathrm{H}_{5} \mathrm{CH}_{2} \mathrm{CH}_{2} \bullet\right)$. The rate constants in the case of the $\mathrm{H}$-atom abstractions yielding $\mathrm{C}_{8} \mathrm{H}_{9}$ radicals have been derived from those used for the formation of benzyl radicals from toluene, with a correction for the number of abstractable $\mathrm{H}$-atoms. The rate constants in the case of the $\mathrm{H}$-atom abstractions forming $\mathrm{C}_{8} \mathrm{H}_{9}-1$ radicals have been obtained using the correlation proposed by Dean and Bozzelli for the abstraction of $\mathrm{H}$-atoms from hydrocarbons:

$$
k=n_{H} A T^{n} \exp \left(-\left\{E_{0}-f\left(\Delta H_{0}-\Delta H\right)\right\} / R T\right)
$$

where $n_{H}$ is the number of abstractable $\mathrm{H}$-atoms; $A, n$, and $E_{0}$ are the rate parameters for the case of a metathesis by the considered radical from ethane; $\Delta H_{0}$ and $\Delta H$ are the enthalpies of the metatheses by the considered radical from ethane and by the considered radical from the reacting molecule, respectively; $f$ is a correlation factor for each considered radical [29]; and $R$ is the gas constant. Ipso-additions to ethylbenzene of $\mathrm{O}$ and $\mathrm{H}$-atoms (reactions 4 and 5 ), as well as of hydroxyl and methyl radicals (reactions 6 and 7), have also been taken into account. 
Both radicals deriving from ethylbenzene by $\mathrm{H}$-atom abstractions lead to the formation of styrene, by decompositions involving the breaking of a $\mathrm{C}-\mathrm{H}$ bond (reactions (28 and 29)) or by reactions with oxygen molecules (31 and 32), or combine with $\cdot \mathrm{HO}_{2}$ radicals (reactions 33 and 34 ) to give hydroperoxide molecules, which quickly decompose. The rate constant of the decomposition of these hydroperoxides by the scission of the $\mathrm{O}-\mathrm{O}$ bond (reaction 36) was estimated according to Sahetchian et al. [33]. In the case of resonance stabilized $\mathrm{C}_{8} \mathrm{H}_{9}$ radical, the resulting alcoxy radical can decompose by breaking $\mathrm{C}-\mathrm{C}$ bonds, yielding methyl or phenyl radical, respectively (reactions 37 and 39 ), or a $\mathrm{C}-\mathrm{H}$ bond yielding acetophenone (reaction 38). Rate constants were estimated as that for the decompositions of but-3-en-1-oxy radical calculated by Rauk et al. [34]. Acetophenone can also be produced directly from the hydroperoxide by a roaming reaction, where the leaving $\mathrm{OH}$ group abstract directly the $\mathrm{H}$-atom bounded to the $\mathrm{C}$-atom bearing the hydroperoxide function (reaction 35). The rate constant was taken equal to that calculated theoretically in the case of a linear alkylhydroperoxide with the CBS-QB3 method with Gaussian09 [17]. $\mathrm{C}_{8} \mathrm{H}_{9}-1$ radicals can also decompose to give ethylene and phenyl radicals through reaction (30) and $\mathrm{C}_{8} \mathrm{H}_{9}$ radicals can combine with methyl radicals to form cumene (reaction 40 ).

The secondary mechanism is very similar to that initially proposed by Bounaceur et al. [8]. Only the reaction of styrene with $\mathrm{HO}_{2}$ radicals to give phenyloxirane which rapidly isomerize to give phenylacetaldehyde or acetophenone has been added (see Table S2 in Supplementary data). In addition to the sub-mechanisms proposed by Tian et al. for naphthalene and indene [35], three submechanisms including the reactions of cumene, methylstyrene (the two first mechanisms being taken from Pousse et al. [36]) and benzofuran have been added specifically for this study. Note that no reaction in these primary and secondary mechanisms involves the opening of the aromatic cycle. All these changes are documented in Supplementary data.

\section{Comparison between experimental results and modeling}

All of the calculations have been performed using the CHEMKIN software package [13]. Simulation profiles have been compared to the experimental results obtained in a jet-stirred reactor presented in this study, but also to literature data obtained in a plug flow reactor at $1056 \mathrm{~K}$ and atmospheric pressure by Litzinger et al. [5]. Simulations were performed using both PSR and SENKIN codes, respectively, and assuming homogeneous isothermal reactors. In Figures 1 to 4 , points are experiments and lines are model predictions.

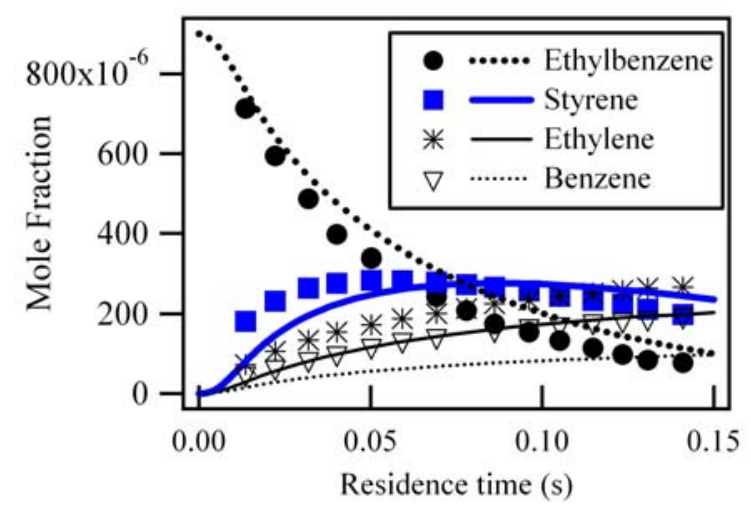

Figure 4. Current ethylbenzene model predictions compared with experimental data obtained in turbulent flow reactor [5] for reactant and major intermediate species evolution with residence time. 


\subsection{Jet-stirred reactor experiments at atmospheric pressure (present study)}

Comparisons of mole fraction measurements of species with simulations are shown in Figures 1 to 3 . The conversion of reactants is very well predicted by the model at all equivalence ratios studied, as well as the formation of carbon oxides, ethylene, acetylene, allene, propyne, acrolein, benzene, toluene, methylstyrene and the sum of phenol and benzofuran. The formation of acetaldehyde, propene, 1,3-butadiene, cyclopentadiene, cresols, and phenylacetaldehyde is underestimated with a significant deviation in the case of propene and 1,3-butadiene. The formation of ethane, cumene, and acetophenone is significantly overestimated. The formation of benzaldehyde and styrene is well reproduced under lean and stoichiometric conditions, but underestimated in rich mixtures. Generally, the largest deviations are encountered in rich mixtures. This is certainly due to the fact that the formation of large polycyclic hydrocarbons and soot was not taken into account in our model, while some experimental evidences of this formation were found under these conditions.

\subsection{Plug-flow reactor}

In order to extend the validity of the model, the results of Litzinger et al. [5], which were obtained in a flow reactor at $1056 \mathrm{~K}$ at atmospheric pressure, with nitrogen as a bath gas, for an initial mole fraction of ethylbenzene of $900 \mathrm{ppm}$ and for an equivalence ratio of 0.95 have also been modeled. No shift of the initial time was made in simulations. Figure 4 displays comparisons between the experimental and computed mole fractions of reactants and some main products. This figure shows good agreement between experiment and the current ethylbenzene model. The reactant consumption is accurately predicted, as well as the formation of major products, such as styrene or ethylene, but the formation of benzene is underestimated. Note that in the case of benzene the agreement is less satisfactory than for the jet-stirred reactor data.

\section{Discussion}

Figure 5 shows a reaction rate analysis for simulations considering a jet stirred reactor for a temperature of $900 \mathrm{~K}$ under the conditions of Figures 1 to 3 (for stoichiometric mixtures) corresponding to a $54 \%$ conversion of ethylbenzene. 


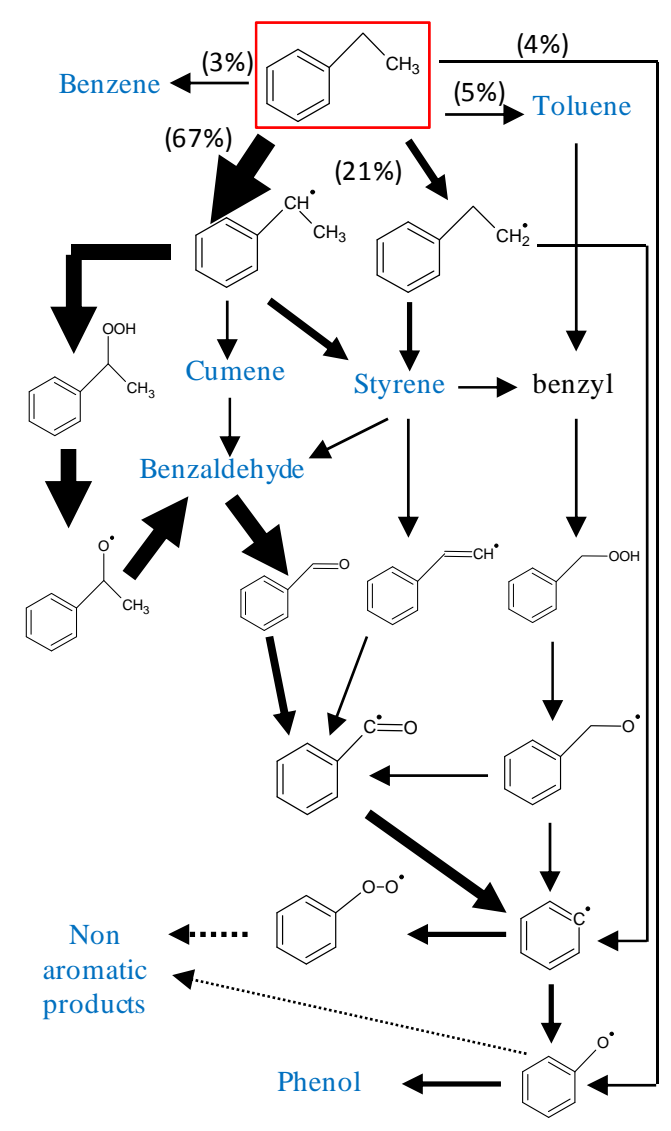

Fig. 5. Flow rate analysis under the conditions of Figures 1 to 3 at $900 \mathrm{~K}$ for stoichiometric mixtures. The size of the arrows is proportional to that of the flow rates and dotted arrows represent a series of reactions.

Under these conditions, $67 \%$ of ethylbenzene is consumed by $\mathrm{H}$-abstractions to form the resonance stabilized $\mathrm{C}_{8} \mathrm{H}_{9}$ radicals, $21 \%$ to produce $\mathrm{C}_{8} \mathrm{H}_{9}-1$ radicals, $3 \%$ by ipso-addition of $\mathrm{H}$-atoms yielding benzene and ethyl radicals, $4 \%$ by ipso-addition of $O$-atoms giving phenoxy and ethyl radicals and $5 \%$ by ipso-addition of methyl radicals producing toluene and ethyl radicals. Ipso-additions are the major pathways to form benzene and toluene. Phenoxy radicals lead mainly to phenol by disproportionation with $\bullet \mathrm{HO}_{2}$ radicals. At $900 \mathrm{~K}$, in a jet-stirred reactor, the reactions of $\mathrm{HO}_{2}$ radicals are of larger importance than at higher temperature or in reactive systems in which $\mathrm{H}$-atoms are present in large amounts, e.g., flames.

The two major pathways to consuming $\mathrm{C}_{8} \mathrm{H}_{9}$ radicals are by reaction with oxygen molecules to give styrene and by combination with $\mathrm{HO}_{2}$ radicals yielding a hydroperoxide. Figure 5 shows well the importance of the combinations of $\mathrm{HO}_{2}$ radicals with resonance stabilized radicals, which has already been observed in the case of alkenes [32]. A very minor channel is the recombination of $\mathrm{C}_{8} \mathrm{H}_{9}$ radicals with methyl radical to produce cumene (reaction 40). The decomposition of the obtained hydroperoxide by reaction (35) contributes to only $4 \%$ to the formation of acetophenone (mainly formed by reaction (38) and from styrene), but its main reaction is by $\mathrm{O}-\mathrm{O}$ bond scission to give an alkoxy radical which decompose mainly to yield methyl radicals and benzaldehyde (reaction 37). This last reaction is the major source of benzaldehyde. The large formation of ethane and cumene is certainly due to an excess of formation of methyl radicals, which are mainly formed through this reaction (37). The three major pathways of consumption of $\mathrm{C}_{8} \mathrm{H}_{9}-1$ radicals are by scission of a $\mathrm{C}-\mathrm{C}$ bond to give ethylene and phenyl radicals, by scission of a $\mathrm{C}-\mathrm{H}$ bond and by reaction with oxygen 
molecules, these last two reactions being the important sources of styrene. Phenyl radicals react mainly with oxygen molecules to produce phenoxy radicals, mainly via phenylperoxy radicals. Phenoxy radicals react mainly with $\mathrm{HO}_{2}$ radicals yielding phenol, but minor consumption pathways also include the formation of benzofuran by reaction with acetylene and decomposition to give carbon monoxide and cyclopentadienyl radicals, a source of cyclopentadiene and then of other nonaromatic products. This last reaction is, by far, the major reaction leading to the opening of the aromatic cycle. Cresols derive mainly from toluene through disproportionation with $\mathrm{HO}_{2}$ of methylphenoxy radicals, which are obtained by ipso-addition of $\mathrm{O}$-atoms or by $\mathrm{H}$-atom abstraction of a phenylic $\mathrm{H}$-atom followed by reaction with oxygen molecules. Methylstyrene is mainly obtained from cumene by $\mathrm{H}$-atom abstraction followed by a $\mathrm{C}-\mathrm{H}$ bond scission. Phenylacetaldehyde is mainly obtained from styrene by addition of $\mathrm{O}$-atoms and of $\mathrm{HO}_{2}$ radicals.

\section{Conclusion}

This paper presents new experimental measurements for the oxidation of ethylbenzene, an important intermediate in the combustion chemistry of aromatic compounds. The mole fraction profiles for reactants and 25 products have been measured in a jet-stirred reactor at temperature from 500 to $1100 \mathrm{~K}$, and at equivalence ratios of $0.25,1$ and 2 . Using these results, a previous mechanism for the oxidation of toluene has been improved and can now quantitatively reproduce the experimental results obtained in this study, as well as others from the literature.

\section{Acknowledgment}

This study has been supported by SAUDI ARAMCO.

\section{References}

[1] F. Battin-Leclerc, Prog. Energy Combust. Sci., 34 (4) (2008), pp. 440-498

[2] W.J. Pitz, N.P. Cernansky, F.L. Dryer, et al., SAE 2007-01-0175, 2007.

[3] C. Ellis, M.S. Scott, R.W. Walker, Combust. Flame, 132 (2003), pp. 291-304

[4] C. Venkat, K. Brezinsky, I. Glassman, Symp. (Int.) Combust. 19 (1982) 143-152.

[5] T.A. Litzinger, K. Brezinsky, I. Glassman, Combust. Flame, 63 (1986), pp. 251-267

[6] A. Roubaud, R. Minetti, L.R. Sochet, Combust. Flame, 121 (2000), pp. 535-541

[7] H.P.S. Shen, M. Oehlschlaeger, Combust. Flame, 156 (2009), pp. 1053-1062

[8] R. Bounaceur, I. Da Costa, R. Fournet, F. Billaud, F. Battin-Leclerc, Int. J. Chem. Kinet., 37 (2005), pp. 25-49

[9] J. Biet, M.H. Hakka, V. Warth, P.A. Glaude, F. Battin-Leclerc, Energy Fuels, 22 (2008), pp. 2258-2269

[10] B. Husson, R. Bounaceur, K. Tanaka et al., Combust. Flame, 159 (2012), pp. 1399-1416 
[11] H.A. Gueniche, J. Biet, P.A. Glaude, R. Fournet, F. Battin-Leclerc, Fuel, 88 (2009), pp. 13881393

[12] I. Da Costa, R. Fournet, F. Billaud, F. Battin-Leclerc, Int. J. Chem. Kinet., 35 (2003), pp. 503524

[13] R.J. Kee, F.M. Ruplay, J.A. Miller, Sandia Laboratories Report S 89-8009B, 1993.

[14] C. Muller, V. Michel, G. Scacchi, G.M. Come, J. Chem. Phys., 92 (1995), p. 1154

[15] S.W. Benson, Thermochemical Kinetics (second ed.)Wiley, New York (1976)

[16] E. Goos, A. Burcat, Br. Ruscic, Ideal Gas Thermochemical Database with updates from Active Thermochemical Tables, available at ftp://ftp.technion.ac.il/pub/supported/aetdd/thermodynamics, 12- 9-2011.

[17] M.J. Frisch, G.W. Trucks, H.B. Schlegel, et al., Gaussian03, revision D02, Gaussian, Inc.: Wallingford, CT, 2004.).

[18] J.A. Montgomery, M.J. Frisch, J.W. Ochterski, G.A. Petersson, J. Chem. Phys., 110 (1999), pp. $2822-2827$

[19] J. Troe, Combust. Flame, 158 (2011), pp. 594-601

[20] E. Heckmann, H. Hippler, J. Troe, Proc. Combust. Inst., 26 (1996), pp. 543-550

[21] A.B. Lovell, K. Brezinsky, L. Glassman, Int. J. Chem. Kinet., 21 (1989), pp. 547-560

[22] Z.Y. Tian, W.J. Pitz, R. Fournet, P.A. Glaude, F. Battin-Leclerc, Proc. Combust. Inst., 33 (2011), pp. 233-241

[23] H. Herbinet, B. Husson, M. Ferrari, P. A. Glaude, F. Battin-Leclerc, Proc. Combust. Inst. 34 (2013), pp. 297-305

[24] W. Muller-Markgraf, J. Troe, J. Phys. Chem., 92 (1988), p. 4914

[25] V. Warth, N. Stef, P.A. Glaude, F. Battin-Leclerc, G. Scacchi, G.M. Côme, Combust. Flame, 114 (1998), pp. 81-102

[26] T. Ingham, R.W. Walker, R.E. Woolford, Proc. Combust. Inst., 25 (1994), pp. 767-774

[27] F. Buda, R. Bounaceur, V. Warth, P.A. Glaude, R. Fournet, F. Battin-Leclerc, Combust. Flame, 142 (2005), pp. 170-186

[28] D. Robaugh, W. Tsang, J. Phys. Chem., 90 (1986), pp. 4159-4163

[29] A.M. Dean, J.W. Bozzelli, W.C. Gardiner (Ed.), Gas-phase Combustion Chemistry, SpringerVerlag, New York (2000)

[30] J. Park, S. Gheyas, M.C. Lin, Int. J. Chem. Kinet., 33 (2001), pp. 64-69 
[31] B. Sirjean, P.A. Glaude, M.F. Ruiz-Lopèz, R. Fournet, J. Phys. Chem. A, 112 (2008), pp. $11598-11610$

[32] R. Touchard, R. Fournet, P.A. Glaude et al., Proc. Combust. Inst., 30 (2005), pp. 10731081

[33] K.A. Sahetchian, R. Rigny, J. Tardieu de Maleissye, L. Batt, M. Anwar Khan, S. Mathews, Proc. Combust. Inst., 24 (1992), pp. 637-643

[34] A. Rauk, R.J. Boyd, S.L. Boyd, D.J. Henry, L. Radom, Can. J. Chem., 81 (2003), pp. 431-442

[35] E. Pousse, Z. Tian, P.A. Glaude, R. Fournet, F. Battin-Leclerc, Combust. Flame, 157 (2010), pp. 1236-1260

[36] E. Pousse, P.A. Glaude, R. Fournet, F. Battin-Leclerc, Combust. Flame, 156 (2009), pp. 954-974 